CORRESPONDENCE

\title{
Late and very late relapsed acute lymphoblastic leukemia: clinical and molecular features, and treatment outcomes
}

(c) The Author(s) 2021

\author{
Blood Cancer Journal (2021)11:125; https://doi.org/10.1038/s41408-021-00516-1
}

Acute lymphoblastic leukemia (ALL) often relapse early after the treatment course, within the first two years from the initial diagnosis [1-3]. Cases of late relapse (LR) occurring in $\geq 5$ years from initial diagnosis have been reported infrequently [4-6]. However, there is no exact definition for late/very late relapse of ALL. Vora et al., reported 12 cases $(\sim 1 \%)$ with very-late relapse (VLR), defined as $>10$ years from the time of complete remission $(\mathrm{CR})$, among 1134 children treated on the Medical Research Council (MRC) ALL trials [5]. The MRC UKALLXII/ECOG E2993 reported that $2.8 \%(n=21)$ of all relapses in adult ALL patients were late ( $\geq 5$ years from remission) [6]. Rizzari et al. showed that LR ALL ( $\geq 5$ years) occurred in $2.9 \%$ of Italian children, with a median onset of 6.1 years (range: 5.8-13.7) [4]. It remains unknown if LR results from recurrence of the original leukemia or from a second de novo ALL that is clonally distinct from to the original malignancy. To better understand the clonal origin of LRALL and examine treatment outcomes, we analyzed genetic features and clinical outcomes including response to novel agents (i.e., blinatumomab and inotuzumab) [7, 8], and/or allogeneic hematopoietic cell transplantation (alloHCT) in patients treated for ALL at City of Hope $(\mathrm{COH})$.

Of 1280 patients with ALL treated at $\mathrm{COH}$ from 2000 to 2020, we identified 36 patients who had their first relapse in $\geq 5$ years after their original diagnosis. This study was approved by our Institutional Review Board. We defined LR and VLR as relapse occurring 5-9 years and $\geq 10$ years after the initial ALL diagnosis, respectively.

Available archived paired DNA samples (collected at diagnosis and relapse, $n=3$ ) were analyzed by next generation sequencing (NGS) for genomic alterations and clonal relationship. Supplementary Table 1 shows the clinically significant pathogenic variants and variants of unknown significance from three pairs of samples. Supplementary Fig. 1 is the schematic presentation of clinically significant variants and variants of unknown significance on a genomic scale. Genomic alterations detected were compared between the time points for each patient. Descriptive statistics were used for patient and leukemia characteristics by LR-ALL and VLR-ALL. $X^{2}$ and Wilcoxon tests were used to examine differences in the categorical and continuous characteristics by two groups of patients, respectively. All tests were two-sided at a 0.05 level. Analysis was conducted using SAS version 9.4 (SAS Institute, Cary, NC).

Patient and leukemia characteristics $(n=36)$ are shown in Table 1. Briefly, among patients with LR-ALL, the median latency period from the original diagnosis to the first relapse was 7 years (range: 5-28). There were 12 patients (33\%) who had their first relapse $\geq$ 10 years after the initial diagnosis, with a median of 20 years (range: 10-28), and 24 patients who relapsed in 5-9 years of postoriginal diagnosis, with a median of 6 years (range: $5-9$ ). With the exception of one patient, none of the LR-ALL or VLR-ALL cases had their first relapse occurred after alloHCT.

Leukemia lineage at the time of initial diagnosis was B-cell in most patients ( $n=32,89 \%)$, and the remaining cases were T-cell lineage $\operatorname{ALL}(n=4)$. No instances of lineage switch were detected at relapse. Among the 18 cases with available cytogenetics data at initial diagnosis and first relapse, seven patients had different cytogenetics at first relapse. There were three cases with $K M T 2 A$ gene rearrangement (KMT2Ar) detected at relapse. Among these, one patient had $K M T 2 A r$ detected at initial diagnosis, one patient did not have $K M T 2 A r$ at initial diagnosis, and one patient had unknown initial cytogenetics diagnosis (Table 1).

Refer to Supplementary Table 2 for initial and first salvage therapies in LR-ALL and administered novel therapies. A flow chart explaining the sequence of treatments is shown in Supplementary Fig. 2. The CR2 rate with salvage therapy at the time of first relapse was $93 \%(n=33)$. Three patients required $2(n=2)$ or $3(n=1)$ cycles of re-induction to attain CR2. Novel therapies administered upon late relapse were blinatumomab $(n=9 ; C R=7)$, inotuzumab $(n=2 ; \mathrm{CR}=2)$ and chimeric antigen receptor (CAR) T cells $(n=3$; $\mathrm{CR}=1)$. Post-relapse, $28(78 \%)$ patients underwent alloHCT, of whom 20 (71\%) patients were transplanted in CR2, 7 (25\%) were transplanted in CR3 and one was transplanted after the second relapse.

With a median follow-up from first relapse of 6 years (range: 0.2-20.7), median leukemia-free survival (LFS) and overall survival (OS) were 4.4 years (range: 1.9-6.3) and 14.9 years (range: $5.5-\mathrm{NE}$ ) for all patients, respectively. No difference in 5 -year LFS (43\% vs. $56 \%, p=0.83)$ and OS (73\% vs. $63 \%, p=0.70)$ were observed between patients with LR-ALL and VLR-ALL. (Fig. 1).

The median follow-up for patients who underwent alloHCT post-first relapse was 4.7 years (range: $0.4-20.7)$ from the date of transplant. Non-relapse mortality (NRM) at 1 and 5 years were $11 \%$ and $24 \%$, respectively. Relapse rate post-HCT were $16 \%$ and $35 \%$ at 1 and 5 years, respectively. LFS and OS at 5 years were $40 \%$ and $61 \%$, respectively. No difference was observed in OS $(p=0.92)$, LFS $(p=0.78)$, relapse rate $(p=0.29)$, or NRM $(p=0.15)$ between patients with LR-ALL and VLR-ALL following alloHCT (Fig. 1). Landmark analysis at 1-year of post 1st relapse, no difference in OS between patients who did or did not undergo alloHCT (Supplementary Fig. 3).

Three paired samples obtained at diagnosis and relapse were tested by an NGS panel. The latency periods from diagnosis until relapse were 5,5 , and 10 years. In all three cases, the mutation profiles were different and did not support a clonal relationship, thereby indicating distinct genetics between the original and LRALL (Supplementary Table 2 and Supplementary Fig. 3).

Herein, we have described a cohort of patients with LR-ALL $(n=36)$, a third of whom had their first relapse in $\geq 10$ years after 
Table 1. Patient and leukemia characteristics.

\begin{tabular}{|c|c|c|c|c|}
\hline & $\begin{array}{l}\text { Late relapse ( } 5-9 \text { years }) \\
(N=24)\end{array}$ & $\begin{array}{l}\text { Very late relapse ( } \geq 10 \text { years) } \\
(N=12)\end{array}$ & Total $(N=36)$ & $P$ value \\
\hline Median (Range) & $16(4-35)$ & $16(3-40)$ & $16(3-40)$ & \\
\hline Age at first relapse & & & & 0.005 \\
\hline Median (Range) & $23(9-42)$ & $35(22-51)$ & $25(9-51)$ & \\
\hline Female & $7(29.2 \%)$ & $4(33.3 \%)$ & $11(30.6 \%)$ & \\
\hline Male & $17(70.8 \%)$ & $8(66.7 \%)$ & 25 (69.4\%) & \\
\hline Race & & & & 0.54 \\
\hline Asian & $1(4.2 \%)$ & $0(0 \%)$ & $1(2.8 \%)$ & \\
\hline Hispanic & $11(45.8 \%)$ & $9(75 \%)$ & $20(55.6 \%)$ & \\
\hline Phenotype at diagnosis & & & & 1.00 \\
\hline B cell & $21(87.5 \%)$ & $11(91.7 \%)$ & 32 (88.9\%) & \\
\hline $\mathrm{T}$ cell & $3(12.5 \%)$ & $1(8.3 \%)$ & $4(11.1 \%)$ & \\
\hline \multicolumn{5}{|c|}{$\begin{array}{l}\text { Times from first diagnosis to 1st relapse } \\
\text { (years) }\end{array}$} \\
\hline Median (Range) & $6(5-9)$ & $20(10-28)$ & $7(5-28)$ & \\
\hline Interquartile range & 5,7 & 13,23 & 6,13 & \\
\hline CNS & & & & 0.47 \\
\hline NO & 19 (79.2\%) & $9(75 \%)$ & $28(77.8 \%)$ & \\
\hline YES (diagnosis + relapse) & $0(0 \%)$ & $1(8.3 \%)$ & $1(2.8 \%)$ & \\
\hline Cytogenetics at diagnosis & & & & 0.62 \\
\hline KMT2A (MLL) & $1(4.3 \%)$ & $1(8.3 \%)$ & $2(5.6 \%)$ & \\
\hline Normal Karyotype & $8(34.8 \%)$ & $2(16.7 \%)$ & $10(27.8 \%)$ & \\
\hline Others & $4(17.4 \%)$ & $1(8.3 \%)$ & $5(13.9 \%)$ & \\
\hline $\mathrm{Ph}+$ & $1(4.3 \%)$ & $1(8.3 \%)$ & $2(5.6 \%)$ & \\
\hline Unknown/Missing & $10(41.7 \%)$ & $7(58.3 \%)$ & $17(47.2 \%)$ & \\
\hline Cytogenetics at 1 st relapse & & & & 0.92 \\
\hline Complex & $2(8.3 \%)$ & $1(8.3 \%)$ & $3(8.3 \%)$ & \\
\hline KMT2A (MLL) & $2(8.3 \%)$ & $1(8.3 \%)$ & $3(8.3 \%)$ & \\
\hline NK & $10(41.7 \%)$ & $4(33.3 \%)$ & $14(38.9 \%)$ & \\
\hline Others & $4(16.7 \%)$ & $1(8.3 \%)$ & $5(13.9 \%)$ & \\
\hline $\mathrm{Ph}+$ & $1(4.2 \%)$ & $2(16.7 \%)$ & $3(8.3 \%)$ & \\
\hline Unknown/Missing & $5(20.8 \%)$ & $3(25 \%)$ & $8(22.2 \%)$ & \\
\hline \multicolumn{5}{|l|}{ Location of 1 st relapse } \\
\hline $\mathrm{BM}$ & $20(83.3 \%)$ & $8(66.7 \%)$ & $28(77.8 \%)$ & 0.21 \\
\hline Combined & $3(12.5 \%)$ & $1(8.3 \%)$ & $4(11.1 \%)$ & \\
\hline EMD & $1(4.2 \%)$ & $3(25 \%)$ & $4(11.1 \%)$ & \\
\hline
\end{tabular}


A

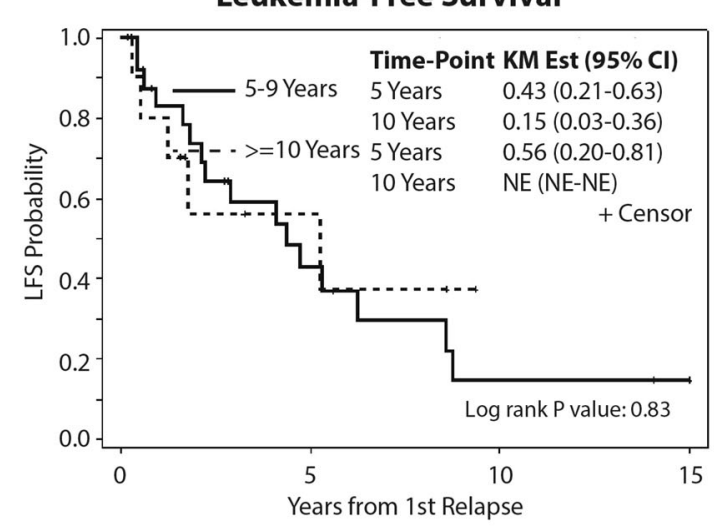

C

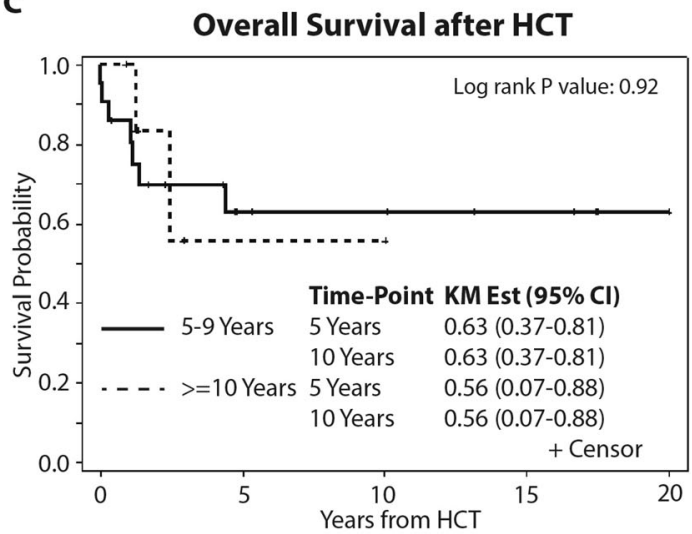

E

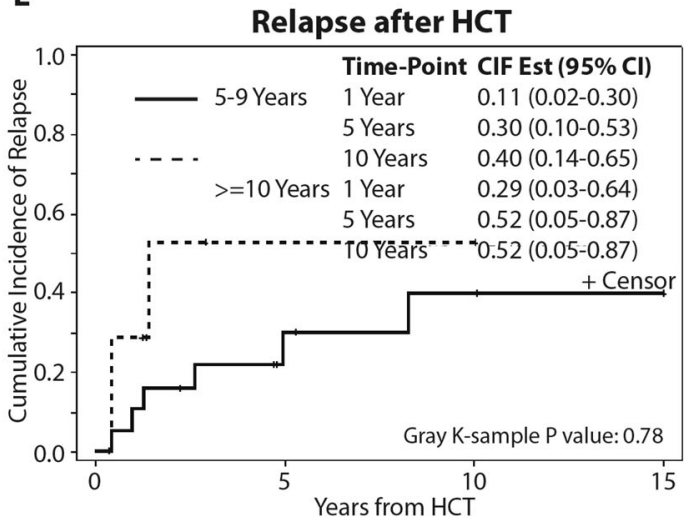

B

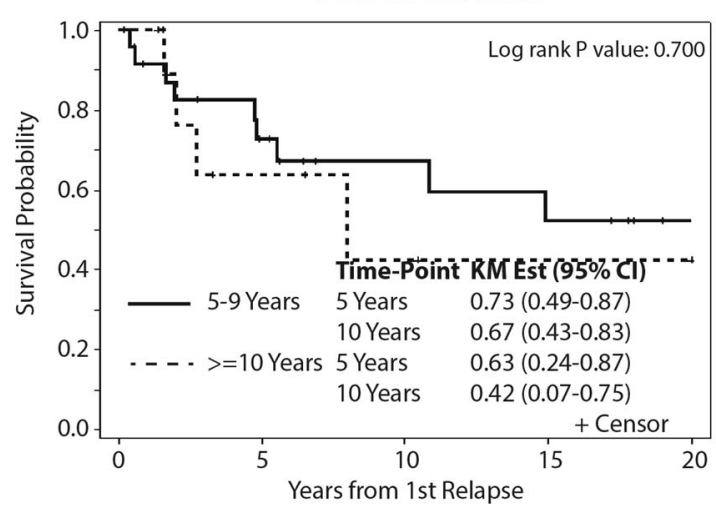

D Leukemia-Free Survival after HCT

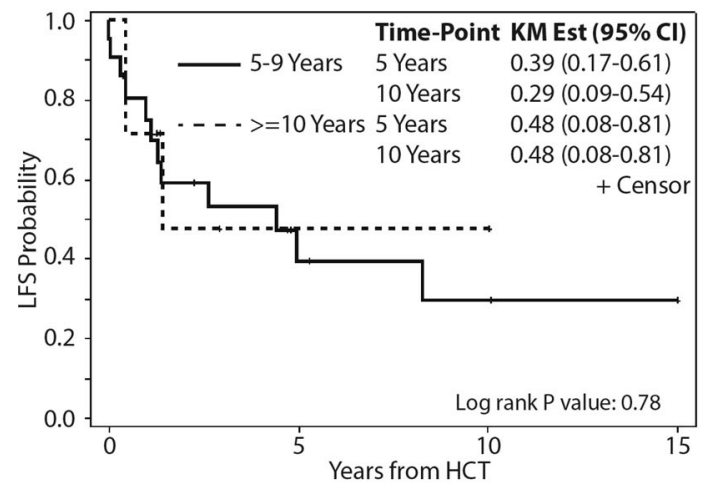

F

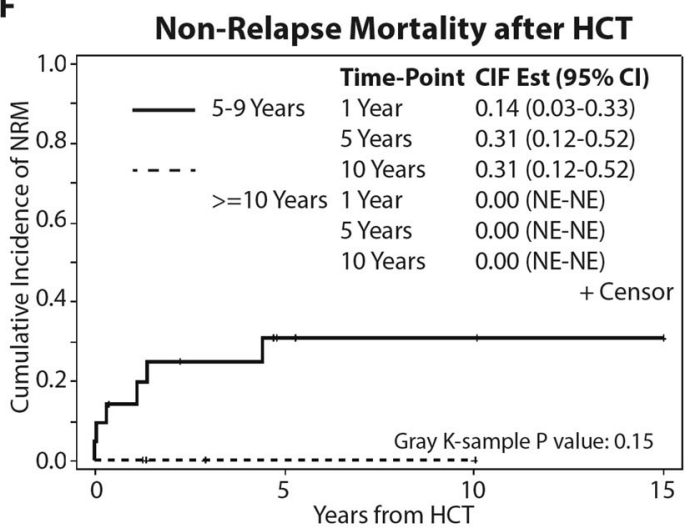

Fig. 1 Outcomes of late and very late relapse outcomes. A Leukemia-free survival after late relapse. B Overall survival after late relapse. C Overall survival after HCT. D Leukemia-free survival after HCT, E Relapse after HCT, and D Non-relapse mortality after HCT. Overall survival and leukemia-free survival were compared using Kaplan-Meier curves and log-rank tests. Non-relapse mortality and time to relapse were assessed using cumulative incidence curves.

their original diagnosis. Interestingly, in two cases, ALL relapse occurred in $\sim 30$ years after the initial diagnosis, raising the question "if relapse was of the original disease or from a de novo ALL?". In our cohort, LR-ALL occurred mostly in patients who did not undergo alloHCT consolidation, suggesting that LR-ALL might be more relevant to chemotherapy-based treatments.

In our cohort, we did not observe any characteristic differences between LR-ALL and VRL-ALL and no unique patterns of leukemia genetics were detected. We suspect that a large subset of LR- ALL patients in our cohort had a true relapse rather than a de novo ALL, supported by similar lineage (B-cell or T-cell) and cytogenetics profile (over half of the cases) at the time of first relapse.
Interestingly, in some cases, KMT2Ar and complex cytogenetics were detected as new findings compared to the initial cytogenetics; increasing the possibility of de novo secondary disease from prior exposure to chemotherapy (i.e., therapyrelated ALL) [9]. Our hypothesis is further supported by our NGS analysis of paired samples $(n=3)$ showing nonoverlapping pathogenic mutations between the diagnosis and relapse samples. However, this finding could also be related to the known phenomena of genetic evolution of leukemia at the time of relapse [10], or the possibility of previously undetectable small clones contributing to late relapse. 
In a study by Vora et al., molecular analysis of 8 cases with VLRALL showed identical TCR or IgH gene rearrangement at diagnosis and relapse, supporting the concept that LR-ALL could derive from the original clones [5]. In contrast, Ford et al., reported LR-ALL in two cases with TEL-AML1 ALL that was not derived from the initial clone; and postulated that relapse was possibly independent/de novo and emerged form dormant pre-leukemic clones [11].

In our cohort, LR-ALL remained sensitive to conventional chemotherapy as CR rate was $93 \%$ in response to first salvage regimen, and the majority of patients were able to proceed to alloHCT. A subset of our patients received various novel therapies and attained remission. Overall long-term outcomes were encouraging, with over half the patients surviving beyond 5 years from their LR-ALL.

Our study has limitations related to its small size, retrospective nature, and availability of only a handful of paired samples suitable for genetic analysis that could provide additional insight into the origin of LR-ALL. However, our patients with LR-ALL and VLR-ALL had high response rates to re-induction therapy and encouraging outcomes were observed with novel therapies and alloHCT. Larger analysis of paired samples is warranted to gain more insight into the origin of this entity.

Ibrahim Aldoss $\mathbb{D}^{1 凶}$, Raju Pillai ${ }^{2}$, Dongyun Yang ${ }^{3}$, Lixin Yang ${ }^{2}$, Shukaib Arslan ${ }^{1}$, Sally Mokhtari ${ }^{1}$, Monzr M. Al Malki ${ }^{1}{ }^{1}$, Amandeep Salhotra', Shilpa Shahani ${ }^{4}$, Haris Ali ${ }^{1}{ }^{1}$,

Matthew Mei (iD) ${ }^{1}$, Andrew Artz ${ }^{1}$, David Snyder ${ }^{1}$, Michelle Afkhami ${ }^{2}$, Saro Armenian (iD ${ }^{4}$, Anthony Stein ${ }^{1}$, Guido Marcucci ${ }^{1}$,

Stephen J. Forman ${ }^{1}$, Ryotaro Nakamura ${ }^{1,5}$ and Vinod Pullarkat ${ }^{1,5}$

${ }^{1}$ Department of Hematology and Hematopoietic Cell

Transplantation, Gehr Family Center for Leukemia Research, City of

Hope, Duarte, CA, USA. 'Department of Pathology, City of Hope,

Duarte, CA, USA. ${ }^{3}$ Department of Computational and Quantitative

Medicine, City of Hope, Duarte, CA, USA. ${ }^{4}$ Department of Pediatrics,

City of Hope, Duarte, CA, USA. ${ }^{5}$ These authors contributed equally: Ryotaro Nakamura, Vinod Pullarkat. ${ }^{凶}$ email: ialdoss@coh.org

\section{REFERENCES}

1. Nguyen K, Devidas M, Cheng SC, La M, Raetz EA, Carroll WL, et al. Factors influencing survival after relapse from acute lymphoblastic leukemia: a Children's Oncology Group study. Leukemia. 2008;22:2142-50.

2. Gaynon PS, Qu RP, Chappell RJ, Willoughby ML, Tubergen DG, Steinherz PG, et al. Survival after relapse in childhood acute lymphoblastic leukemia: impact of site and time to first relapse-the Children's Cancer Group Experience. Cancer. 1998;82:1387-95.

3. Fielding AK, Richards SM, Chopra R, Lazarus HM, Litzow MR, Buck G, et al. Outcome of 609 adults after relapse of acute lymphoblastic leukemia (ALL); an MRC UKALL12/ECOG 2993 study. Blood. 2007;109:944-50.

4. Rizzari C, Valsecchi MG, Aricò M, Miniero R, Messina C, De Rossi G, et al. Outcome of very late relapse in children with acute lymphoblastic leukemia. Haematologica. 2004;89:427-34.

5. Vora A, Frost L, Goodeve A, Wilson G, Ireland RM, Lilleyman J, et al. Late relapsing childhood lymphoblastic leukemia. Blood. 1998;92:2334-7.

6. Ganzel C, Wang XV, Rowe JM, Richards SM, Buck G, Marks DI, et al. At three years, patients with acute lymphoblastic leukaemia are still at risk for relapse. Results of the international MRC UKALLXII/ECOG E2993 trial. Br J Haematol. 2020;191:37-43. https://doi.org/10.1111/bjh.16616.

7. Kantarjian H, Stein A, Gökbuget N, Fielding AK, Schuh AC, Ribera JM, et al. Blinatumomab versus chemotherapy for advanced acute lymphoblastic leukemia. $\mathrm{N}$ Engl J Med. 2017;376:836-47.
8. Kantarjian HM, DeAngelo DJ, Stelljes M, Martinelli G, Liedtke M, Stock W, et al. Inotuzumab ozogamicin versus standard therapy for acute lymphoblastic leukemia. N Engl J Med. 2016;375:740-53.

9. Aldoss I, Stiller T, Tsai NC, Song JY, Cao T, Bandara NA, et al. Therapy-related acute lymphoblastic leukemia has distinct clinical and cytogenetic features compared to de novo acute lymphoblastic leukemia, but outcomes are comparable in transplanted patients. Haematologica. 2018;103:1662-8. https://doi.org/10.3324/ haematol.2018.193599

10. Ertz-Archambault N, Kosiorek H, Slack JL, Lonzo ML, Greipp PT, Khera N, et al. Cytogenetic evolution in myeloid neoplasms at relapse after allogeneic hematopoietic cell transplantation: association with previous chemotherapy and effect on survival. Biol Blood Marrow Transplant. 2017;23:782-9.

11. Ford AM, Fasching K, Panzer-Grümayer ER, Koenig M, Haas OA, Greaves MF. Origins of "late" relapse in childhood acute lymphoblastic leukemia with TELAML1 fusion genes. Blood. 2001;98:558-64.

\section{ACKNOWLEDGEMENTS}

This study was partially funded by the NIH, P30 CA033572 grant (Biostatistics Core).

\section{COMPETING INTERESTS}

I.A. serves on an advisory board with Amgen, KiTE, Abbvie and Agios, he is a consultant for Autolus Therapeutics, and he received research support from MacroGenics and Abbvie. A.S. has served as consultant for Kadmon Corporation and research funding from Celgene. R.N. serves on advisory boards with Merck and Celgene and has a research collaboration with Jazz Pharmaceuticals. A.S. is on the speakers' bureau for Amgen, Celgene, and Stemline. G.M. is on the speakers' bureau for Abbvie. V.P. has served on the advisory boards for Abbvie and Jazz Pharmaceuticals and is member of speakers' bureau for Jazz Pharmaceuticals, Amgen, Novartis, and Abbvie. The remaining authors have no relevant conflicts of interest to declare.

\section{ADDITIONAL INFORMATION}

Supplementary information The online version contains supplementary material available at https://doi.org/10.1038/s41408-021-00516-1.

Correspondence and requests for materials should be addressed to I.A.

Reprints and permission information is available at http://www.nature.com/ reprints

Publisher's note Springer Nature remains neutral with regard to jurisdictional claims in published maps and institutional affiliations.

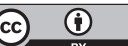

Open Access This article is licensed under a Creative Commons Attribution 4.0 International License, which permits use, sharing, adaptation, distribution and reproduction in any medium or format, as long as you give appropriate credit to the original author(s) and the source, provide a link to the Creative Commons license, and indicate if changes were made. The images or other third party material in this article are included in the article's Creative Commons license, unless indicated otherwise in a credit line to the material. If material is not included in the article's Creative Commons license and your intended use is not permitted by statutory regulation or exceeds the permitted use, you will need to obtain permission directly from the copyright holder. To view a copy of this license, visit http://creativecommons. org/licenses/by/4.0/.

(c) The Author(s) 2021 